\title{
Hybrid laser-arc welding of laser- and plasma-cut 20-mm-thick structural steels
}

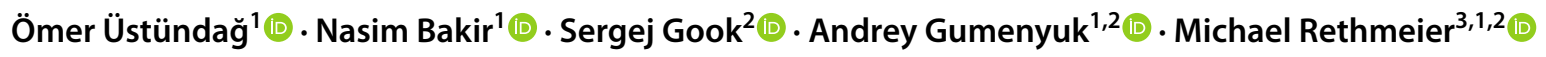

Received: 28 September 2021 / Accepted: 10 January 2022 / Published online: 14 January 2022

(c) The Author(s) 2022

\begin{abstract}
It is already known that the laser beam welding (LBW) or hybrid laser-arc welding (HLAW) processes are sensitive to manufacturing tolerances such as gaps and misalignment of the edges, especially at welding of thick-walled steels due to its narrow beam diameter. Therefore, the joining parts preferably have to be milled. The study deals with the influence of the edge quality, the gap and the misalignment of edges on the weld seam quality of hybrid laser-arc welded 20-mm-thick structural steel plates which were prepared by laser and plasma cutting. Single-pass welds were conducted in butt joint configuration. An AC magnet was used as a contactless backing. It was positioned under the workpiece during the welding process to prevent sagging. The profile of the edges and the gap between the workpieces were measured before welding by a profile scanner or a digital camera, respectively. With a laser beam power of just $13.7 \mathrm{~kW}$, the single-pass welds could be performed. A gap bridgeability up to $1 \mathrm{~mm}$ at laser-cut and $2 \mathrm{~mm}$ at plasma-cut samples could be reached respectively. Furthermore, a misalignment of the edges up to $2 \mathrm{~mm}$ could be welded in a single pass. The new findings may eliminate the need for cost and time-consuming preparation of the edges.
\end{abstract}

Keywords Hybrid laser-arc welding · Thick-walled steel · Edge quality · Gap bridgeability · Misalignment of the edges · Plasma cutting $\cdot$ Laser cutting

\section{Introduction}

Ömer Üstünda $\breve{g}$

oemer.uestuendag@bam.de

Nasim Bakir

nasim.bakir@bam.de

Sergej Gook

sergej.gook@ipk.fraunhofer.de

Andrey Gumenyuk

andrey.gumenyuk@bam.de

Michael Rethmeier

michael.rethmeier@bam.de

1 Bundesanstalt für Materialforschung und -prüfung BAM, Unter den Eichen 87, 12205 Berlin, Germany

2 Fraunhofer Institute for Production Systems and Design Technology, Pascalstraße 8-9, 10587, Berlin, Germany

3 Institute for Machine Tools and Factory Management IWF, Technische Universität Berlin, Pascalstraße 8-9, 10587, Berlin, Germany
The hybrid laser-arc welding (HLAW) process became more importance for joining of thick-walled steels in the last years. It allows high penetration depths due to the high power density of the beam. With the coupling of the laser beam welding process (LBW) and the arc welding process, mostly gas metal arc welding (GMAW), in a common welding zone, the gap bridgeability is increased due to the addition of the filler wire. The effectiveness of the process lies in the reduction of the number of the layers and welding time especially for the welding of thick-walled steels. These bring the economic advantages of the process compared to the common arc welding process such as gas metal arc welding and submerged arc welding (SAW) processes.

Nevertheless, it is well known that the beam-based welding processes such as HLAW are sensitive to gaps between the joining parts, edge quality and misalignment of the edges. Therefore, the joining parts preferably have to be milled which can be time and cost-consuming. Furthermore, the use of an expensive clamping technology is unavoidable to ensure the exact positioning of the joining partners in 
relation to each other. This challenge has already been recognized by the industry and the researchers, so there are several studies on the subject dealing with the gap bridgeability and mismatch at HLAW of wall thicknesses up to $10 \mathrm{~mm}$. For higher wall thicknesses, there are only a few studies.

In already published works, the max. gap bridgeability was $0.8 \mathrm{~mm}$ or $0.35 \mathrm{~mm}$ for welding of structural steels with 15- to 16-mm thickness by a carbon dioxide laser [1] or a solid-state laser [2], respectively. With a transversal oscillation of the laser beam to the welding direction, the max. gap bridgeability was extended to $0.7 \mathrm{~mm}$ by HLAW of 16-mm-thick plates [3]. One-pass 25-mm-thick samples could be welded with 2.5-mm air gap, where the gap was filled with cut-wire particles before welding. For the protection of drop-outs, a backing such as ceramic or flux was used [4]. With the use of the electromagnetic weld pool support, which allows a reduction of the welding speed and thus increasing seam width without a deterioration of the seam quality and formation of sagging, the gap bridgeability could be increased to $1 \mathrm{~mm}$ for single-pass welds of 20 - to $25-\mathrm{mm}$ thick structural steels [5]. The misalignment of edges up to $2 \mathrm{~mm}$ at $16-\mathrm{mm}$ - or $25-\mathrm{mm}$-thick plates could be welded with optimization of the welding speed and with a variation of the focal position [2] or the use of a magnetic backing support [5], respectively.

The influence of the edge quality and morphology on the seam quality has already been confirmed. With an edge surface preparation to the roughness level about $\mathrm{Ra} 6.3 \mu \mathrm{m}$ with an increases air gap of 0.1 to $0.2 \mathrm{~mm}$, a deeper penetration level and a better weld quality could be observed at laser beam welding of up to 20 -mm-thick steels. A further increase of the roughness higher than $\mathrm{Ra} 8 \mu \mathrm{m}$ leads to an unacceptable quality of the seams [6]. For double-sided HLAW of 25-mm-thick steels, it was reported in [7] that milled as well as cut plates obtained by abrasive cutting, plasma cutting and laser cutting can be used. In general, the uniformity and high quality of abrasive water cut surfaces and milled surfaces, which are appropriate for butt joint configuration, enabled a higher stability of the welding process. For plasma-cut samples, the filler material was increased up to $60 \%$ due to the V-shape groove. Laser-cut surfaces required approx. $20 \%$ less laser power for welding, because the striations of the laser-cut surfaces locally increases the air gap at the joints [7]. During HLAW of 12- to 15-mmthick structural steels, the process window was much wider for machined edges compared to plasma-cut edges in regard to the root humping effect and stability of the process [8].
HLAW of laser-cut steels with a wall thickness of $10 \mathrm{~mm}$ and an acceptable weld quality could be determined even with oxides from the cutting process. For higher wall thickness of $12 \mathrm{~mm}$, the oxides have to be removed in order to obtain welds without pores and excessive and irregular weld penetration [9].

The aim of this study is to investigate the effect of the edge quality on the weld seam quality for single-pass HLAW of $20-\mathrm{mm}$-thick structural steels. Additionally, the gap bridgeability and the mismatch of the edges will be studied to identify the sensitivity of the HLAW to the manufacturing tolerances and to expand the range of the industrial applications of the HLAW. To overcome the sagging or root humping, an innovative bath support based on external oscillating magnetic field is applied. The effectiveness of the electromagnetic weld pool support system at LBW has already been demonstrated first by Avilov et al. [10] and for HLAW in the previous studies of the authors [11].

\section{Experiments}

\subsection{Materials}

The welding experiments were conducted on 20-mm-thick structural steel plates of S355J2 in a single-pass butt joint configuration. A solid wire G3Ni1 according to EN ISO 14341-A with a wire diameter of $1.2 \mathrm{~mm}$ was used as filler material. The chemical composition of the materials is shown in Table 1. A mixture of argon with $18 \% \mathrm{CO}_{2}$ with a flow rate of $201 \mathrm{~min}^{-1}$ served as shielding gas.

\subsection{Edge preparation}

Two different cutting procedures were used, namely laser cutting and plasma cutting. The laser cutting experiments were also carried out with the same optical head of the laser, which is actually used for the welding experiments. Only a cutting kit was installed to the optics. The nozzle diameter was $2 \mathrm{~mm}$. The $20-\mathrm{mm}$-thick plates were cut using $5-\mathrm{kW}$ laser power at a cutting speed of $0.2 \mathrm{~m} \mathrm{~min}^{-1}$. The focal position was set to $-8 \mathrm{~mm}$ and the distance between the nozzle and the workpiece was $1 \mathrm{~mm}$. Nitrogen with a pressure of 9.5 bar served as cutting gas. The plasma-cut samples were prefabricated by the steel manufacturer. The cut edges show typical appearances. Striations are present at the laser-cut samples which are well defined on the top of the cut edge
Table 1 Chemical composition of the material used; shown in wt $\%$

\begin{tabular}{lllllllllll}
\hline Material/element & $\mathrm{C}$ & $\mathrm{Mn}$ & $\mathrm{Si}$ & $\mathrm{P}$ & $\mathrm{S}$ & $\mathrm{Cr}$ & $\mathrm{Ni}$ & $\mathrm{Mo}$ & $\mathrm{Cu}$ & $\mathrm{Fe}$ \\
\hline S355J2 & 0.08 & 1.3 & 0.29 & 0.019 & 0.004 & - & - & - & 0.08 & bal \\
G3Ni1 & 0.08 & 1.4 & 0.612 & 0.004 & - & 0.014 & 0.73 & 0.08 & - & bal \\
\hline
\end{tabular}


Fig. 1 Edge morphology of plasma-cut (left) and laser-cut (right) edges

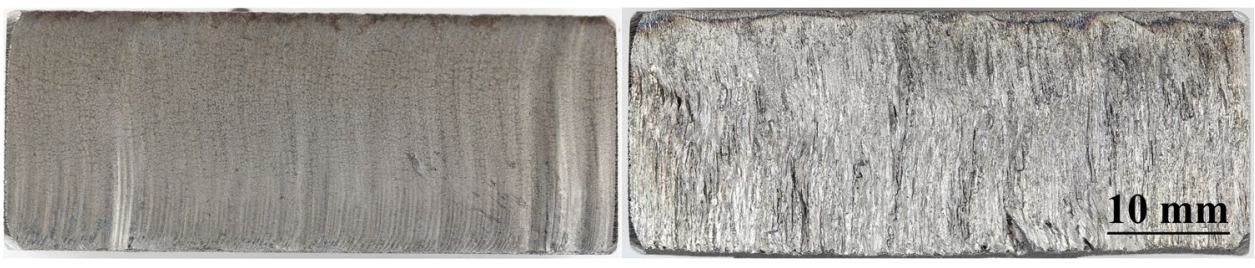

Surface roughness in $\mathrm{mm}$

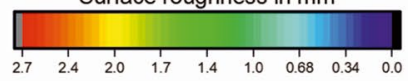

A
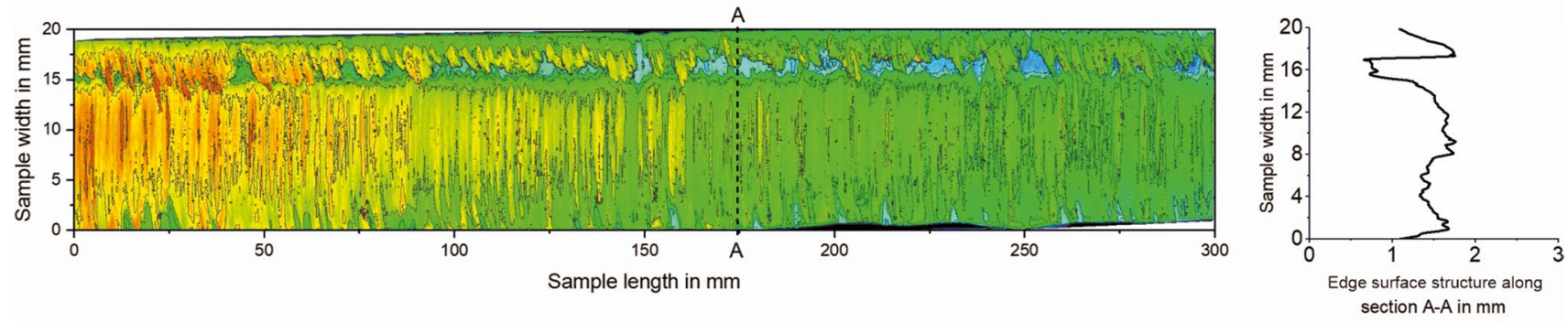

A

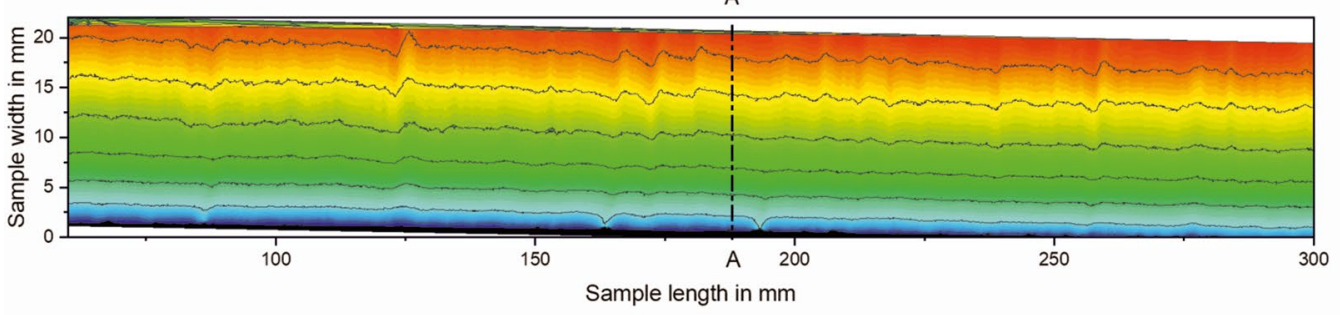

Fig. 2 Edge profile of laser-cut (top) and plasma-cut (bottom) 20-mm-thick S355J2 plate; profile measured by a laser-profile scanner

and become more random towards the bottom. The cut edges are shown in Fig. 1. In general, the cutting experiments were not the main part of this study rather than the influence of the edge quality on the weld seam quality during single-pass HLAW with electromagnetic weld pool support.

The profile of the edges was measured by a laser profile scanner scanCONTROL (from the company MICROEPSILON) with a line linearity of $3 \mu \mathrm{m}$ and a measuring speed up to $10 \mathrm{kHz}$ and a laser wavelength of $405 \mathrm{~nm}$. The travel speed during the measurements was $1.5 \mathrm{~m} \mathrm{~min}^{-1}$. The profile scans are shown in Fig. 2 for laser and plasma-cut edges. For the laser-cut edges, it can be noted that the roughness is much higher than the plasma-cut samples and the edges prepared with laser cutting shows more irregularities such as striations, which are typical for laser beam cutting process. The plasma-cut samples are similar to a V-groove joint preparation.

After a tack weld on the end faces of the samples, the resulting gap on the top surface and bottom surface was measured by a digital camera. Then, the gap on the top surface and bottom surface was calculated using an edge detection tool. Figure 3 and Fig. 4 show the measured gap on the

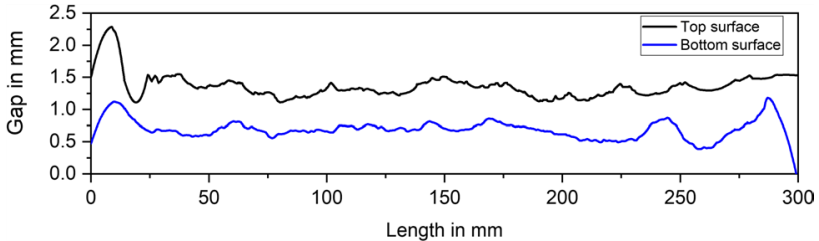

Fig. 3 Gap sizes for the laser-cut samples on the top surface and bottom surface

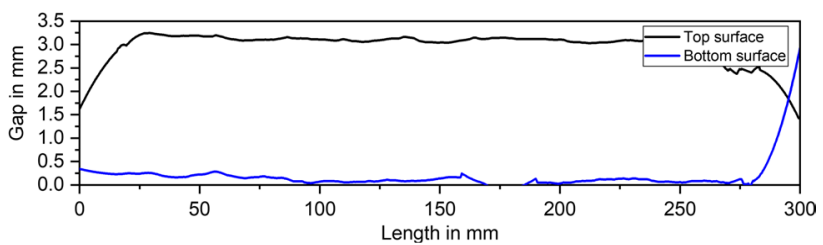

Fig. 4 Gap sizes for the plasma-cut samples on the top surface and bottom surface 
top surface and bottom surface between the two joining parts for laser-cut and plasma-cut samples over the entire plate length of $300 \mathrm{~mm}$, respectively. For the plasma-cut sample, it is recognizable that the gap on the bottom surface nearly $0 \mathrm{~mm}$ indicates that the edge is near to a $\mathrm{V}$-shape.

\subsection{Welding equipment and experimental setup}

For the welding tests, a high-power fibre laser, IPG YLR20000 , with a maximum output power of $20 \mathrm{~kW}$, an emission wavelength of $1070 \mathrm{~nm}$ and a beam parameter product of $11 \mathrm{~mm} \times \mathrm{mrad}$ was used as laser beam source. The laser radiation was transmitted through an optical fibre with a core diameter of $200 \mu \mathrm{m}$. A laser processing head, BIMO $\mathrm{HP}$, with a focal length of $350 \mathrm{~mm}$ providing a spot focus diameter of $0.56 \mathrm{~mm}$ was used. A welding machine, Qineo Pulse 600, with a maximum current of 600 A was applied as a power source for the arc.

The laser optics and GMAW torch were mounted on the robot arm, where the laser axis was positioned $90^{\circ}$ to the weld specimen surface and the GMA torch was tilted $25^{\circ}$ relative to the laser axis, and the position of the robot remains unchanged during welding. For the electromagnetic weld pool support, an AC magnet was positioned $2 \mathrm{~mm}$ below the workpiece. The magnet was operated at an oscillating frequency of $1.2 \mathrm{kHz}$, an $\mathrm{AC}$ power of 1.2 to $1.4 \mathrm{~kW}$ and resulting magnetic flux density of 80 to $100 \mathrm{mT}$. The distance between the two magnet poles was $25 \mathrm{~mm}$. Even, the magnet was in a fixed position during the welding process. The welding trials were performed by the movement of the plates by an external axis. Therefore, the samples were fixed at the external axis. Before welding, the samples were joined by a tack weld on the end faces. All the experiments were carried out with an arc leading orientation and a distance of $4 \mathrm{~mm}$ between the two heat sources. The focal position of the laser beam was $-6 \mathrm{~mm}$ relative to the workpiece surface. The wire stick-out was set to $18 \mathrm{~mm}$. The experimental setup is shown in Fig. 5.

\section{Results and Discussion}

\subsection{Zero-gap and misalignment of edges}

The visual test of the welded joints did not reveal imperfections such as incomplete penetration, sagging or undercuts. The plasma-cut samples were welded in butt joint configuration and zero gap in full penetration mode using a laser beam power $\left(P_{\mathrm{L}}\right)$ of $13.7 \mathrm{~kW}$ at welding speed $\left(v_{\mathrm{w}}\right)$ of $0.75 \mathrm{~m} \mathrm{~min}^{-1}$ and the focal position of the laser beam $\left(z_{\mathrm{f}}\right)$ was $-6 \mathrm{~mm}$. The wire feed speed $\left(v_{\text {wire }}\right)$ and the stickout were $12 \mathrm{~m} \mathrm{~min}^{-1}$ and $18 \mathrm{~mm}$ respectively. The welding current $\left(I_{\text {arc }}\right)$ and voltage $\left(U_{\text {arc }}\right)$ amounted to $326 \mathrm{~A}$ and

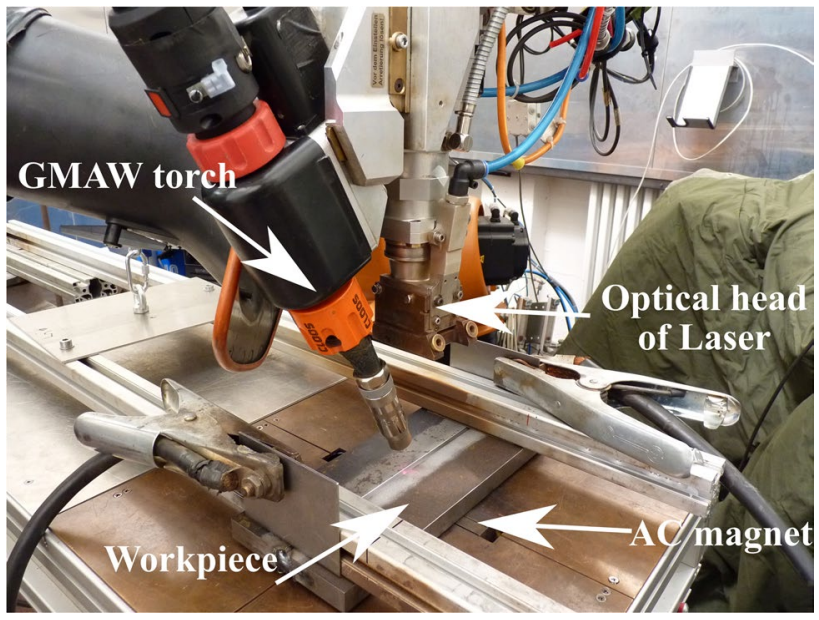

Fig. 5 Experimental setup for hybrid laser-arc welding with electromagnetic weld pool support

$38.7 \mathrm{~V}$ respectively. Figure 6 shows the outer appearance of the hybrid laser-arc welded seam, the X-ray image for the internal inspection and the corresponding cross-section. It can be observed that the root is ideally compensated by the generated electromagnetic pressure over the entire seam length, so the welded joint satisfied the requirements related to quality level B according to ISO 12932. The required magnet power $\left(P_{\mathrm{AC}}\right)$ was $1.4 \mathrm{~kW}$ at an oscillating frequency $\left(f_{\mathrm{AC}}\right)$ of $1.2 \mathrm{kHz}$, which was determined in the previous studies of the authors [11]. The metallographic evaluation of the cross-sectional weld shape formation lets conclude that the full penetrated welds are formed to a wine cup shape which is typical for HLAW.

Additionally, the independence of the cutting side and the welding side is demonstrated, so that samples were welded to the opposite side to their cutting. For this purpose, specimens were aligned with their kerf facing downwards, upwards (reference case) and one of the joining partners at the bottom and the other at the top. With the selected welding parameters, all specimens could be welded without external and internal defects. The samples with the kerf facing downwards show a width of the gap at the root part is approx. $3 \mathrm{~mm}$. A stability criterion for the prevention of the root drops is defined in [10], where a stable process without a drop formation can only be achieved without a backing support, if the width of the root does not exceed approx. $2.5 \mathrm{~mm}$ for a single-pass weld of a $20-\mathrm{mm}$-thick plate. This stability criterion is dependent on the geometrical sizes of the weld seam and the surface tension, which prevents the formation of root drops. But if the seam root width increases to $3 \mathrm{~mm}$ or above, a stable process without root drops cannot be produced without a backing support. As it can be seen for the samples with the kerf downwards, the root width has to be $>3 \mathrm{~mm}$ to ensure a seam without sidewall lack 

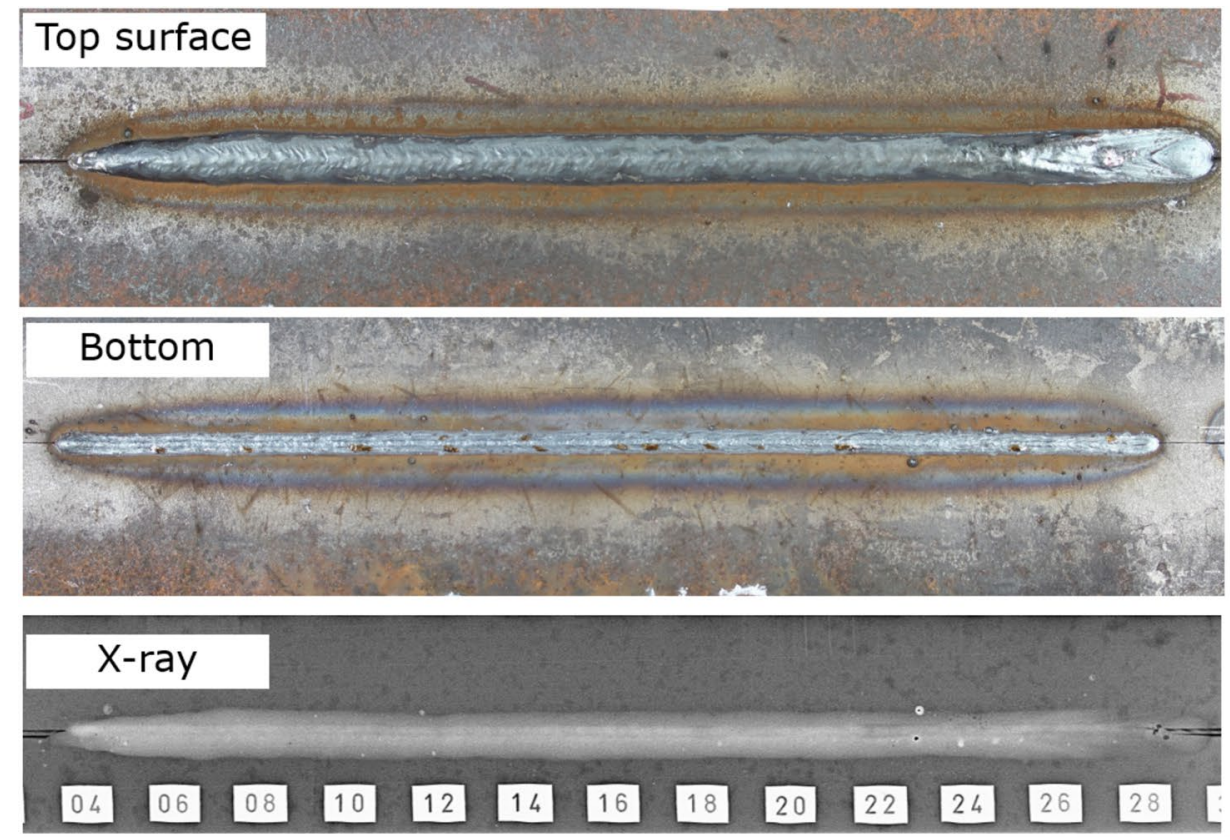

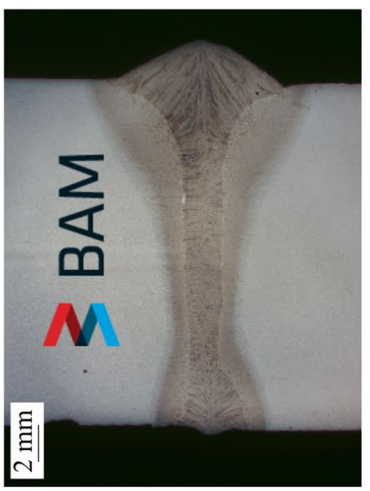

Welding parameters: $\mathrm{P}_{\mathrm{L}}=13.7 \mathrm{~kW} ; \mathrm{v}_{\mathrm{w}}=0.75 \mathrm{~m} \mathrm{~min}^{-1}$ $\mathrm{v}_{\text {wire }}=12 \mathrm{~m} \mathrm{~min}^{-1} ; \mathrm{z}_{\mathrm{f}}=-6 \mathrm{~mm}$ $\mathrm{U}_{\mathrm{arc}}=38.7 \mathrm{~V} ; \mathrm{I}_{\mathrm{arc}}=326 \mathrm{~A}$ $\mathrm{f}_{\mathrm{AC}}=1.2 \mathrm{kHz} ; \mathrm{P}_{\mathrm{AC}}=1.4 \mathrm{~kW}$

Fig. 6 Single-pass HLAW 20-mm-thick plasma-cut S355J2 steel with electromagnetic weld pool support: outer appearance, X-ray image and cross-section

Fig. 7 Cross-sections of singlepass hybrid laser-arc welded plasma-cut 20-mm-thick steels with different kerf orientations
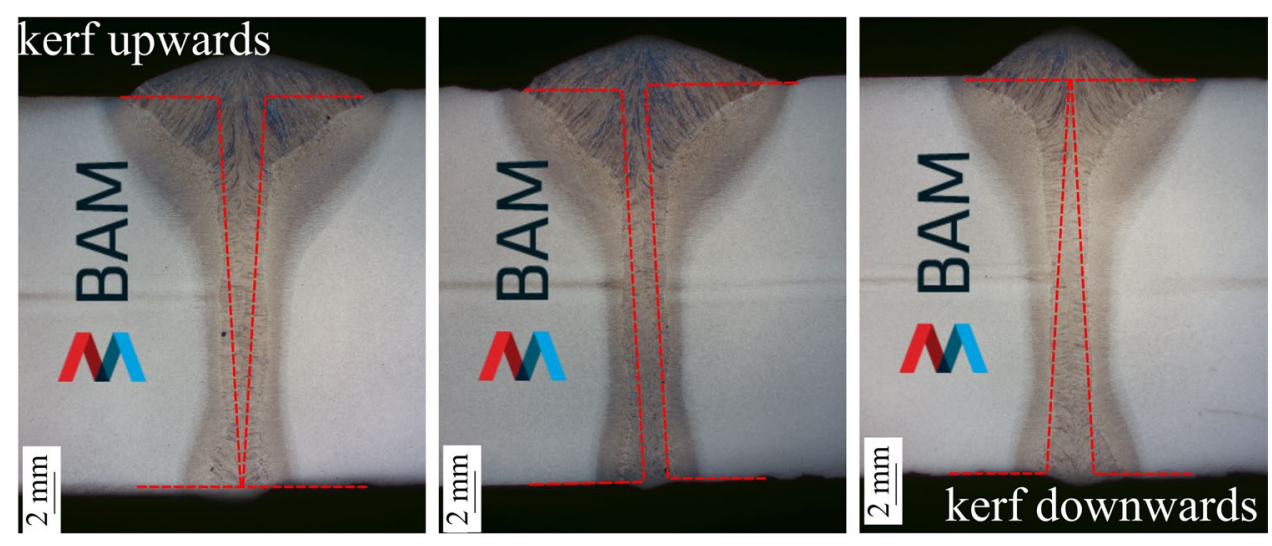

of fusion. Therefore, a backing support is necessary to prevent the root drops. Figure 7 shows the cross-sections of the hybrid laser-arc welded 20-mm-thick plasma-cut steels with different positions of the kerf. The welding parameters remained unchanged. It is recognizable that the weld seam profile for the sample with the kerf facing downwards shows some differences. The width in the root is increased and the seam width on the top side is narrow compared to the others.

The transfer of the welding parameters on the laser-cut specimens was limited due to the changed gap sizes. The gap is influenced by the striations and the cut quality. A lack of sidewall fusion can be recognized, especially at the end of the sample. With increasing weld seam length and the heat accumulation to the end of the seam, the plates open easily at the end. This change in the gap size affects the weld seam quality, as it can be seen in Fig. 8. Lack of sidewall fusion can be detected at a hybrid laser-arc welded laser-cut sample. With an adjustment of the welding speed, the lack of sidewall fusion could be avoided. Therefore, the welding speed was decreased to $0.65 \mathrm{~m} \mathrm{~min}^{-1}$ to increase the weld seam width. The remaining welding parameters are unchanged. Figure 9 shows the outer appearance of the hybrid laser-arc welded laser-cut 20-mm-thick steel plate, the X-ray image for the internal inspection and the corresponding cross-section.

\subsection{Gap bridgeability and misalignment of edges}

Additionally, the gap bridgeability and the misalignment of edges were investigated for the laser-cut and plasma-cut 
Fig. 8 X-ray image of singlepass hybrid laser-arc welded laser-cut 20-mm-thick steel without an adjustment of the welding parameters resulting in lack of sidewall fusion (welding speed of $0.75 \mathrm{~m} \mathrm{~min}^{-1}$ at a laser beam power of $13.7 \mathrm{~kW}$ )

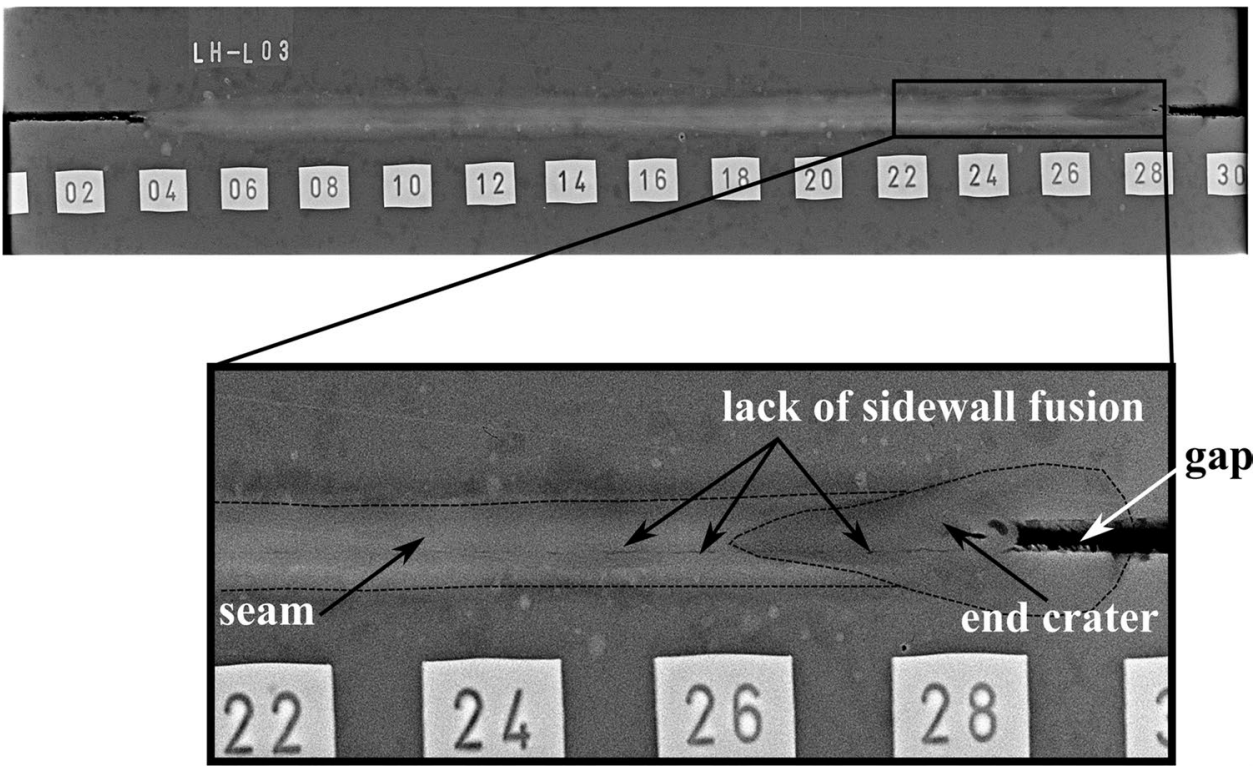

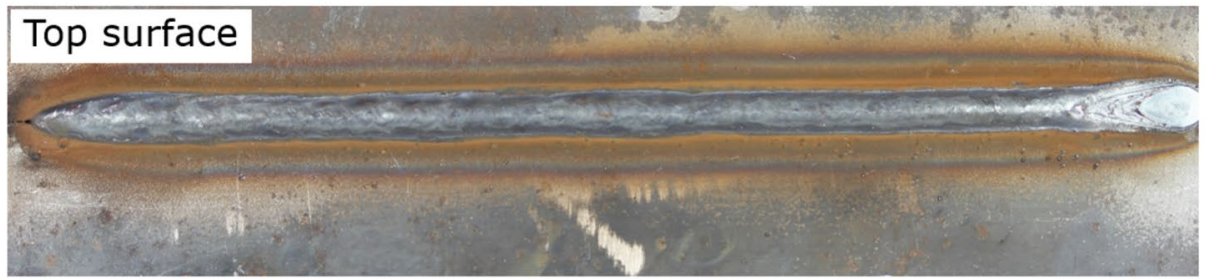
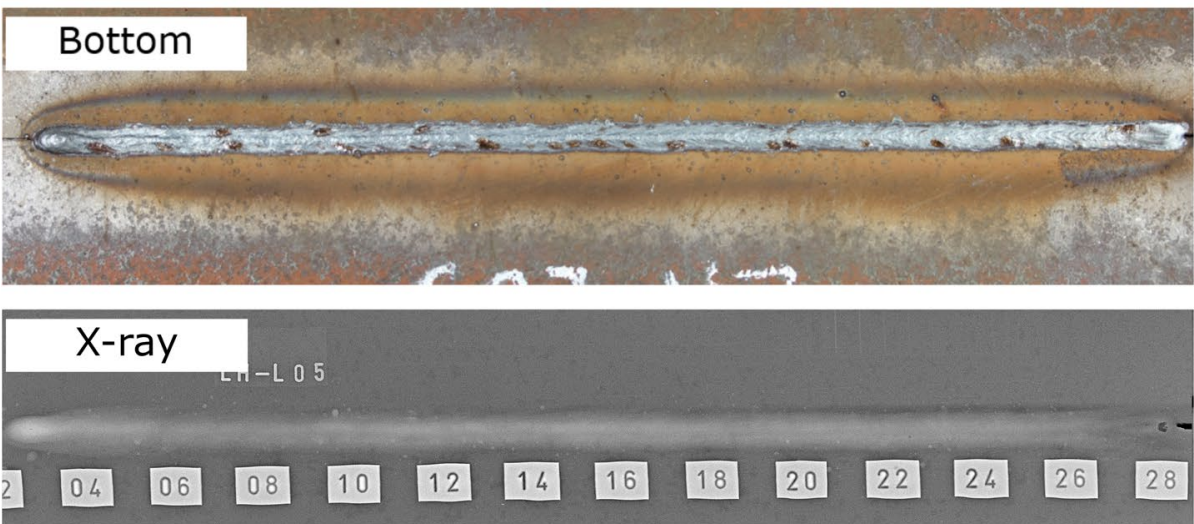

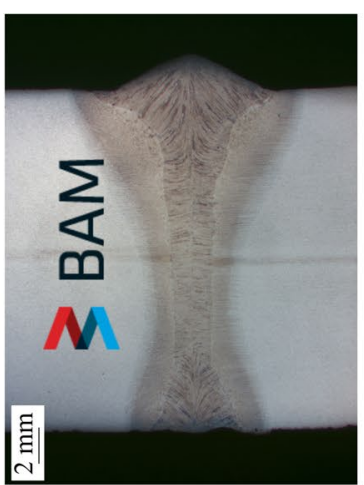

Welding parameters:

$P_{\mathrm{L}}=13.7 \mathrm{~kW} ; \mathrm{v}_{\mathrm{w}}=0.65 \mathrm{~m} \mathrm{~min}^{-1}$

$\mathrm{V}_{\text {wire }}=12 \mathrm{~m} \mathrm{~min}^{-1} ; \mathrm{z}_{\mathrm{f}}=-6 \mathrm{~mm}$

$\mathrm{U}_{\mathrm{arc}}=38.6 \mathrm{~V} ; \mathrm{I}_{\mathrm{arc}}=297 \mathrm{~A}$

$\mathrm{f}_{\mathrm{AC}}=1.2 \mathrm{kHz} ; \mathrm{P}_{\mathrm{AC}}=1.3 \mathrm{~kW}$

Fig. 9 Single-pass HLAW 20-mm-thick laser-cut S355J2 steel with electromagnetic weld pool support: outer appearance, X-ray image and cross-section

20-mm-thick steels. First, a pre-set gap of 0.5 to $1 \mathrm{~mm}$ was employed for the laser-cut samples. This pre-set gap is additional to the natural gap, which arises from the cut quality alone (see Fig. 2). It can be noted that a pre-set gap of $0.5 \mathrm{~mm}$ can be bridged. The welded seam can be classified in the highest evaluation group B according to ISO 12932 with regard to the outer appearance. Internal defects could not be observed in the X-ray images. For a pre-set gap over $1 \mathrm{~mm}$, the stability of the arc welding process is decreased, so that internal defects such as the formation of pores can be detected. The shielding gas cover cannot be guaranteed due to the large gap and the joint cannot be filled with the additional filler wire. With the natural gap size of up to $1.5 \mathrm{~mm}$ (see Fig. 2), the real gap size increases to approx. $2.5 \mathrm{~mm}$. Since the laser beam-based welding processes are characterized by a narrow seam width, especially in the laser-dominated zone, a gap of $2.5 \mathrm{~mm}$ cannot be bridged without additional adaptation of the process, such as the use 
of a scanning movement of the laser beam. The gap sizes mentioned in this study exceeds the gap sizes available in the literature by far. This gap size can be considered as the limit of the single-pass HLAW for 20-mm-thick laser-cut steel plate. The welding parameters had to be adapted for the trials dealing with the gap bridgeability. The welding speed was decreased to $0.5 \mathrm{~m} \mathrm{~min}^{-1}$, the laser power to $12.2 \mathrm{~kW}$ at a pre-set gap size of $0.5 \mathrm{~mm}$ and $11.5 \mathrm{~kW}$ at a gap of $1 \mathrm{~mm}$, and the wire feed speed is increased due to the increasing volume, which have to be filled with increasing gap sizes to $12 \mathrm{~m} \mathrm{~min}^{-1}$ and $13.5 \mathrm{~m} \mathrm{~min}^{-1}$ for a pre-set gap of $0.5 \mathrm{~mm}$ and $1 \mathrm{~mm}$, respectively. The magnet parameters remained unchanged. Figure 9 shows the cross-sections for a singlepass HLAW laser-cut 20-mm-thick steel with zero-gap, preset gap of $0.5 \mathrm{~mm}$ and $1 \mathrm{~mm}$. Additionally, the misalignment of the edges up to $2 \mathrm{~mm}$ could be welded in a single-pass using $13.7-\mathrm{kW}$ laser beam power at a welding speed of $0.65 \mathrm{~m} \mathrm{~min}^{-1}$ and with a wire feed speed of $12 \mathrm{~m} \mathrm{~min}^{-1}$, so without any change of the welding parameters such as for the zero-gap and mismatch case. An adjustment of the welding speed or a change of the focal position was not necessary as reported in [2]. At these welding speeds, a wide enough weld seam width is guaranteed, so that a mismatch of $2 \mathrm{~mm}$ can be bridged safely. A cross-section of a single-pass HLAW 20 -mm-thick laser-cut steel with a mismatch of $2 \mathrm{~mm}$ is shown in Fig. 10. $\delta_{0}$ is the natural gap which appears after the cutting process.

With the transfer of the results to the plasma-cut samples, a gap bridgeability up to $2 \mathrm{~mm}$ could be bridged successfully. Due to the differences in the cut quality and the resulting profile of the edges, a higher gap could be bridged. For the samples with a gap of $0.5 \mathrm{~mm}, 1 \mathrm{~mm}$ and $2 \mathrm{~mm}$, the welding speed was decreased to $0.7 \mathrm{~m} \mathrm{~min}^{-1}, 0.6 \mathrm{~m} \mathrm{~min}^{-1}$ and $0.5 \mathrm{~m} \mathrm{~min}^{-1}$, respectively, to get a wider seam to prevent sidewall lack of fusions. In contrast, the wire feed speed had to be increased up to $15 \mathrm{~m} \mathrm{~min}^{-1}$ due to the higher volume, which had to be filled by the arc welding process. The laser beam power was adjusted to $13.2 \mathrm{~kW}, 12.8 \mathrm{~kW}$ and $12 \mathrm{~kW}$ with increasing gap sizes. The magnet parameters remain unchanged. The misalignment of the edges up to $2 \mathrm{~mm}$ could be welded in a single-pass using $13.7-\mathrm{kW}$ laser beam power at a welding speed of $0.75 \mathrm{~m} \mathrm{~min}^{-1}$ and with a wire feed speed of $12 \mathrm{~m} \mathrm{~min}^{-1}$. The related cross-sections are shown in Fig. 11.

\section{Conclusions}

Experimental investigations on single-pass HLAW of 20-mm-thick steels of S355J2 with different edge preparation, laser-cut and plasma-cut were made. An electromagnetic weld pool support was used as backing support. The experiments show that the sensitivity of the HLAW process to gaps and misalignment of the edges could be reduced with the use of a backing support. For the laser-cut and plasmacut samples, a high gap bridgeability with a pre-set gap up to $1 \mathrm{~mm}$ and $2 \mathrm{~mm}$ could be reached. Compared to the state of the art, this corresponds to an increase of the gap bridgeability up to three times higher. Even with non-milled steels, a high quality of the weld seams could be achieved, which can be classified in the highest evaluation group B according to EN ISO 12932. The new findings would increase the potential industrial application for the high-productive HLAW process. With the use of an electromagnetic bath
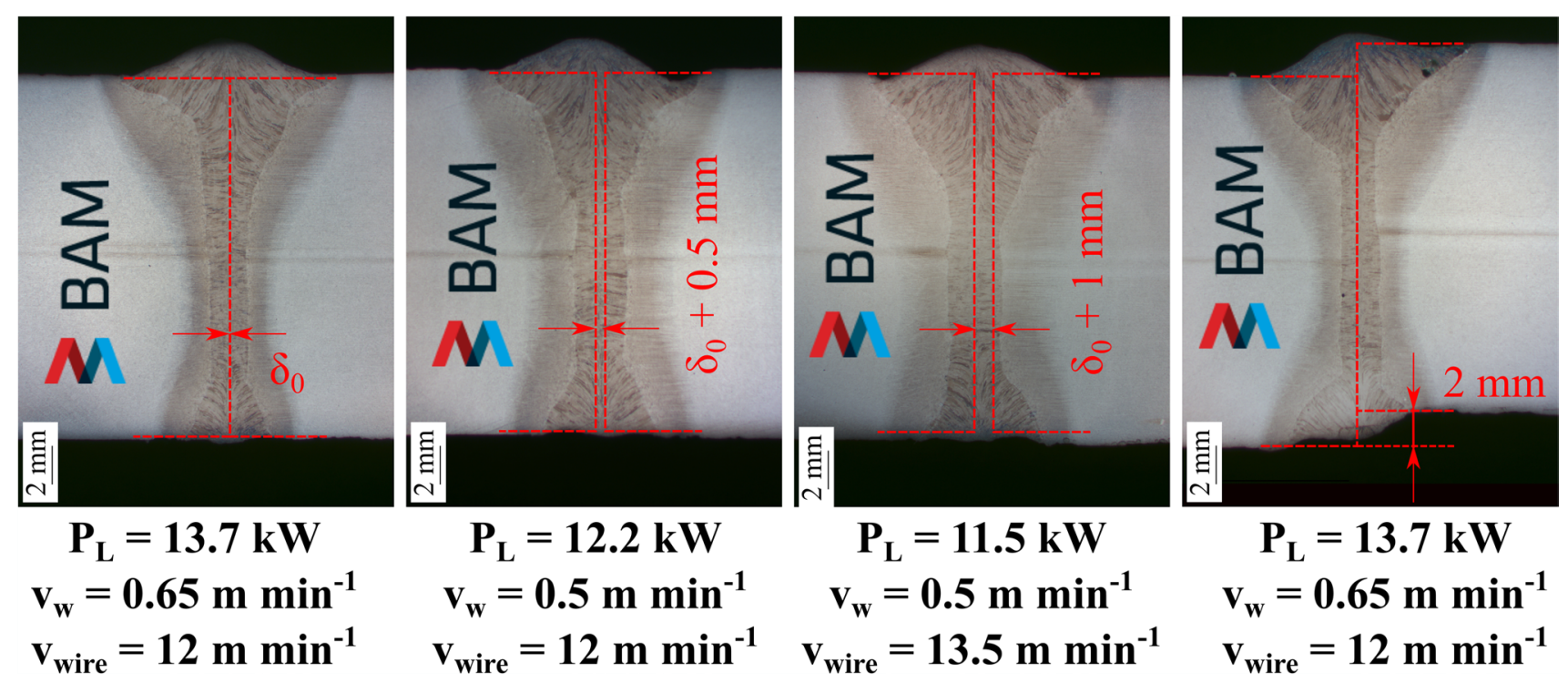

Fig. 10 Cross-sections of single-pass HLAW 20-mm-laser-cut steels of S355J2 with varying gap sizes and misalignment of the edges 


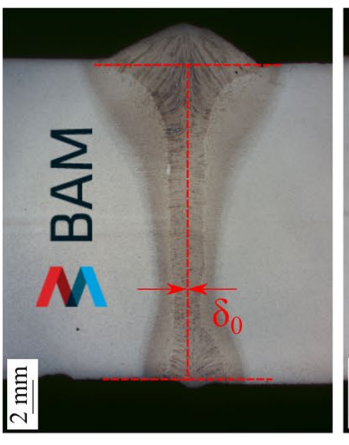

$P_{\mathrm{L}}=13.7 \mathrm{~kW}$

$\mathrm{V}_{\mathrm{w}}=0.75 \mathrm{~m} \mathrm{~min}^{-1}$

$v_{\text {wire }}=12 \mathrm{~m} \mathrm{~min}^{-1}$

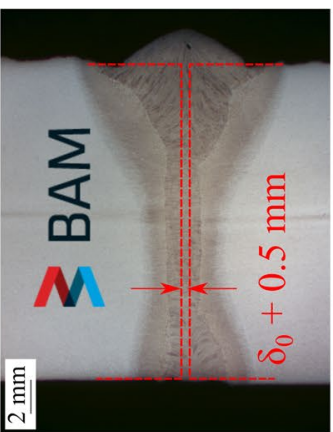

$P_{\mathrm{L}}=13.2 \mathrm{~kW}$

$\mathrm{v}_{\mathrm{w}}=0.7 \mathrm{~m} \mathrm{~min}^{-1}$

$\mathrm{v}_{\text {wire }}=13 \mathrm{~m} \mathrm{~min}^{-1}$

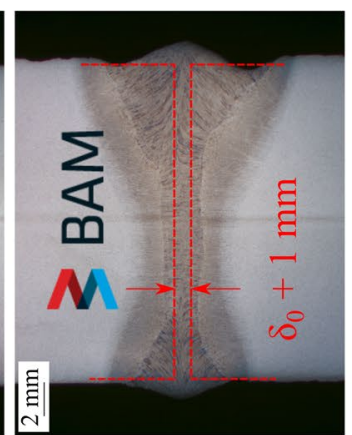

$P_{\mathrm{L}}=12.8 \mathrm{~kW}$

$\mathrm{v}_{\mathrm{w}}=0.6 \mathrm{~m} \mathrm{~min}^{-1}$

$v_{\text {wire }}=13 \mathrm{~m} \mathrm{~min}^{-1}$

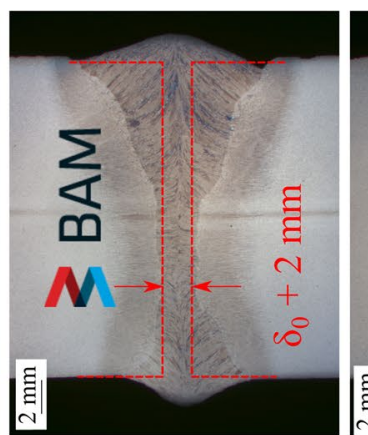

$P_{\mathrm{L}}=12 \mathrm{~kW}$

$\mathrm{v}_{\mathrm{w}}=0.5 \mathrm{~m} \mathrm{~min}^{-1}$

$v_{\text {wire }}=15 \mathrm{~m} \mathrm{~min}^{-1}$

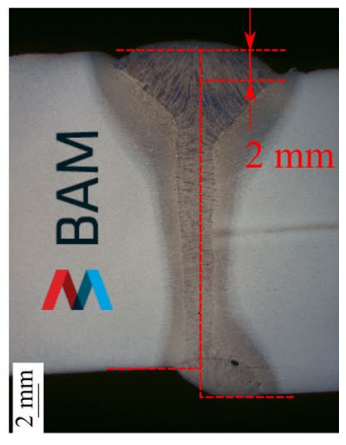

$P_{\mathrm{L}}=13.7 \mathrm{~kW}$ $\mathrm{V}_{\mathrm{w}}=0.75 \mathrm{~m} \mathrm{~min}^{-1}$ $v_{\text {wire }}=12 \mathrm{~m} \mathrm{~min}^{-1}$

Fig. 11 Cross-sections of single-pass HLAW 20-mm-plasma-cut steels of S355J2 with varying gap sizes and misalignment of the edges

support which works contactless, a removal of the conventional backing strips and a rework of the root can be avoided.

Acknowledgements The authors would like to thank Mr. Grunwald from the Division 8.3 (Radiological Methods) of the BAM for the $\mathrm{X}$-ray images.

Funding Open Access funding enabled and organized by Projekt DEAL. The research project was carried out in the framework of the Industrial Collective Research programme (IGF No.20.827 N). It was supported by the Federal Ministry for Economic Affairs and Energy (BMWi) through the AiF (German Federation of Industrial Research Associations e.V.) based on a decision taken by the German Bundestag. Financial funding is gratefully acknowledged.

\section{Declarations}

Conflict of interest The authors declare no competing interests.

Open Access This article is licensed under a Creative Commons Attribution 4.0 International License, which permits use, sharing, adaptation, distribution and reproduction in any medium or format, as long as you give appropriate credit to the original author(s) and the source, provide a link to the Creative Commons licence, and indicate if changes were made. The images or other third party material in this article are included in the article's Creative Commons licence, unless indicated otherwise in a credit line to the material. If material is not included in the article's Creative Commons licence and your intended use is not permitted by statutory regulation or exceeds the permitted use, you will need to obtain permission directly from the copyright holder. To view a copy of this licence, visit http://creativecommons.org/licenses/by/4.0/.

\section{References}

1. Kristensen, J. K. Thick Plate CO2-Laser/MAG Hybrid Welding of Steels. IIW doc. IV-932-07. IIW Annual meeting 2007, Dubrovnik, Croatia.
2. Vollertsen F, Grünenwald S, Rethmeier M, Gumenyuk A, Reisgen U, Olschok S (2010) Welding thick steel plates with fibre lasers and GMAW. Welding in the World 54(3):R62-R70

3. Gook, S., Gumenyuk, A., \& Rethmeier, M. (2010, September). Weld seam formation and mechanical properties of girth welds performed with laser-GMA-hybrid process on pipes of grade X65. In International Congress on Applications of Lasers \& ElectroOptics (Vol. 2010, No. 1, pp. 62-69). Laser Institute of America.

4. Wahba M, Mizutani M, Katayama S (2016) Single pass hybrid laser-arc welding of $25 \mathrm{~mm}$ thick square groove butt joints. Mater Des 97:1-6

5. Üstündağ Ö, Fritzsche A, Avilov V, Gumenyuk A, Rethmeier M (2018) Study of gap and misalignment tolerances at hybrid laser arc welding of thick-walled steel with electromagnetic weld pool support system. Procedia Cirp 74:757-760

6. Sokolov M, Salminen A (2012) Experimental investigation of the influence of edge morphology in high power fiber laser welding. Phys Procedia 39:33-42

7. Farrokhi F, Nielsen SE, Schmidt RH, Pedersen SS, Kristiansen M (2015) Effect of cut quality on hybrid laser arc welding of thick section steels. Phys Procedia 78:65-73

8. Bunaziv, I., Dørum, C., Nielsen, S. E., Suikkanen, P., Ren, X., Nyhus, B., Eriksson, M., \& Akselsen, O. M. (2020). Laser-arc hybrid welding of 12-and 15-mm thick structural steel. The International Journal of Advanced Manufacturing Technology, 1-21.

9. Engström, H., Nilsson, K., Flinkfeldt, J., Nilsson, T., Skirfors, A., \& Gustavsson, B. (2001, October). Laser hybrid welding of high strength steels. In International Congress on Applications of Lasers \& Electro-Optics (Vol. 2001, No. 1, pp. 125-134). Laser Institute of America.

10. Avilov, V. V., Moldovan, R., Berger, P., \& Graf, T. (2008). Electromagnetic weld pool control system for laser beam welding of thick metal plates. Proceedings of the IWOTE08, 413-20.

11. Üstündağ Ö, Fritzsche A, Avilov V, Gumenyuk A, Rethmeier M (2018) Hybrid laser-arc welding of thick-walled ferromagnetic steels with electromagnetic weld pool support. Welding in the World 62(4):767-774

Publisher's Note Springer Nature remains neutral with regard to jurisdictional claims in published maps and institutional affiliations. 